\title{
Platelet aggregation measurement for assessment of hemostasis failure mechanisms in patients with gastroduodenal ulcer bleeding
}

This article was published in the following Dove Press journal:

Clinical and Experimental Gastroenterology

2 August 2013

Number of times this article has been viewed

\author{
Edward Barinov' \\ Oksana Sulaieva' \\ Yuriy Lyakch ${ }^{2}$ \\ Vitaliy Guryanov ${ }^{2}$ \\ Petr Kondratenko 3 \\ Yevgeniy Radenko 3 \\ 'Department of Histology, Cytology, \\ and Embryology, ${ }^{2}$ Department of \\ Medical, Biological Physics, Medical \\ Informatics, and Biostatistics, \\ ${ }^{3}$ Department of Surgery and \\ Endoscopy, M Gorky Donetsk \\ National Medical University, \\ Donetsk, Ukraine
}

Background: The purpose of this study was to identify factors associated with the risk of unsustainable hemostasis in patients with gastric and duodenal ulcer bleeding by in vitro assessment of platelet reactivity using artificial neural networks.

Methods: Patients with gastroduodenal ulcers complicated by bleeding were studied. Platelet aggregation was measured using aggregometry with adenosine diphosphate $5 \mu \mathrm{M}$, epinephrine $2.5 \mu \mathrm{M}$, 5-hydroxytryptophan $10 \mu \mathrm{M}$, collagen $1 \mu \mathrm{M}$, and thrombin $0.06 \mathrm{NIH}$ Unit $/ \mathrm{mL}$ as agonists. Multiple logistic regression was used to evaluate the independent relationship between demographic, clinical, endoscopic, and laboratory data and in vitro assessment of platelet reactivity and local parameters of hemostasis in patients with ulcer bleeding.

Results: Analysis of platelet aggregation in patients with gastroduodenal ulcer bleeding allowed the variability of platelet response to different agonists used in effective concentration which induces $50 \%$ platelet aggregation $\left(\mathrm{EC}_{50}\right)$ to be established. The relationship between platelet aggregation and the spatial-temporal characteristics of ulcers complicated by bleeding was demonstrated. Adrenoreactivity of platelets was associated with time elapsed since the start of ulcer bleeding and degree of hemorrhage. The lowest platelet response to collagen and thrombin was detected in patients with active bleeding $(P<0.001)$ and unsustainable recent bleeding $(P<0.01)$. Decreased adenosine diphosphate-induced platelet aggregation in patients with ulcer bleeding was correlated with the platelet response to thrombin $(r=0.714, P<0.001)$ and collagen $(r=0.584, P<0.01)$.

Conclusion: Estimation of platelet reactivity in vitro indicates the key mechanisms of failure of hemostasis in patients with ulcer bleeding. In addition to gender, an important determinant of unsustainable hemostasis was a decreased platelet response to thrombin and adenosine diphosphate.

Keywords: ulcer, hemostasis, blood platelets

\section{Introduction}

Gastric and duodenal ulcer bleeding is a common cause of hospital admission and is a life-threatening medical emergency. ${ }^{1,2}$ Recent studies of clinical, laboratory, and endoscopic features of peptic ulcers and their complications have shown that there is a long list of factors associated with this pathology. ${ }^{3-8}$

Nowadays, recommendations for the stepwise management of patients with overt upper gastrointestinal bleeding are based on features such as hemodynamic status, comorbidities, age, laboratory tests, and results of upper endoscopy. ${ }^{9-12}$ However, this approach does not allow us to answer the question of why vascular injury in the region of the ulcer is not accompanied by effective thrombogenesis and sustained hemostasis. It is unclear which defects in hemostasis are associated with development of bleeding and what regulators or mechanisms are key in determination of successful hemosta-
Correspondence: Oksana Sulaieva Department of Histology, Cytology, and Embryology, M Gorky Donetsk National Medical University, Illicha Ave 16, Donetsk, Ukraine 83003 Tel +3809938094I7

Email oksana.sulaeva@dsmu.edu.ua 
sis. This situation can be explained partly by the complex regulation of the hemostasis system.

The integrative link in the hemostasis system is platelets, which are the first cells activated at the site of injury, and are closely related to the plasma coagulation system, endothelium, and connective tissue homeostasis. ${ }^{13}$ These blood cells have numerous receptors for the different molecules involved in regulation and achievement of blood clotting. ${ }^{14}$ Therefore, we felt that in vitro assessment of the reactions of platelets to different stimuli could be useful for understanding unstable hemostasis and establishment of pathogenetic mechanisms of unsustainable thrombogenesis after bleeding. The aim of this study was to identify factors associated with the risk of unsustainable hemostasis in patients with gastric and duodenal ulcer bleeding by in vitro assessment of platelet reactivity using artificial neural networks.

\section{Materials and methods}

\section{Clinical, laboratory, and endoscopic assessment}

A cohort study was conducted in 247 patients with a diagnosis of gastroduodenal ulcer bleeding enrolled between January 1, 2010 and June 30, 2012 at State Hospital 16, Donetsk, Ukraine. Patients considered eligible for enrollment were over 18 years of age and suffering typical symptoms of acute bleeding from gastric and duodenal ulcers confirmed by positive upper gastrointestinal endoscopy. Exclusion criteria were: age younger than 18 years or over 75 years; any allergy to established medication; coagulopathy; myocardial infarction or ischemic stroke in the last 6 months; pregnancy; cirrhosis; and use of steroids, proton pump inhibitors, or $\mathrm{H} 2$ receptor antagonists in the 2 weeks prior to enrollment in the study. Patients with malignant ulcers or trauma were also excluded.

We analyzed the impact of patient demographic characteristics, time from first bleeding symptoms to hospital admission, associated diagnoses, drugs being taken at the time of admission, clinical presentation, and initial laboratory tests (erythrocyte count, hemoglobin, and hematocrit) on the outcome of hemostasis.

We abstracted data describing endoscopic management, including endoscopic diagnosis and the presence of symptoms of active and recent bleeding. The endoscopic diagnosis, ulcer location, lesion size, and symptoms of recent hemorrhage were recorded. Symptoms of recent hemorrhage were evaluated using the Forrest classification, which is commonly used when stratifying patients with upper gastrointestinal hemorrhage into high-risk and low-risk categories for mortality. It is also a helpful method for predicting the risk of rebleeding. ${ }^{7,15}$

Patients were divided into two groups according to initial endoscopic data as having low-risk lesions (sustained hemostasis, Forrest grade IIC and III) ${ }^{1}$ or high-risk lesions (unsustained hemostasis, Forrest grade I and IIA-B). Patients who had endoscopic stigmata of unsustained hemostasis were included into the second group.

\section{Assessment of platelet reactivity}

Whole blood for in vitro study was sampled from patients with peptic ulcer bleeding at the time of hospital admission and before therapy. Blood was collected from the antecubital vein into plastic syringes containing sodium citrate at a final concentration of $0.38 \%$ with a proportion of $9: 1$, and centrifuged at $200 \times \mathrm{g}$ for 20 minutes at $25^{\circ} \mathrm{C}$ to prepare platelet-rich plasma. We evaluated platelet aggregation in the presence of the following agonists: adenosine diphosphate (ADP) $5 \mu \mathrm{M}$, epinephrine $2.5 \mu \mathrm{M}, 5$-hydroxytryptophan (5-HT) $10 \mu \mathrm{M}$, collagen $1 \mu \mathrm{M}$, and thrombin $(0.06 \mathrm{NIH}$ Unit $/ \mathrm{mL})$. The reaction tubes were preincubated for 1 minute at $37^{\circ} \mathrm{C}$, after which $20 \mu \mathrm{L}$ of each agonist was added at an effective concentration inducing $50 \%$ platelet aggregation $\left(\mathrm{EC}_{50}\right)$ concentration. Measurement of platelet aggregation was carried out using an aggregometer (490-2D, Chrono-log Corporation, Havertown, PA, USA) according to a method previously described. ${ }^{16}$ Collagen, ADP, epinephrine, and thrombin were from Chrono$\log$, and the 5-HT was from Sigma (St Louis, MO, USA).

\section{Statistical analysis}

Data were collected and analyzed using MedCalc version 12.3 statistical software (MedCalc Software Inc, Broekstraat, Belgium). ${ }^{17}$ Descriptive statistics were used to analyze and report the data. For presentation of nominal data, the percentage and standard error were calculated; for presentation of numeric data, the median and standard error were calculated. ${ }^{18}$ Chi-square, Kruskal-Wallis, and Dunn's tests were used to determine differences between patients with sustained and unsustainable hemostasis. Multiple logistic regression was used to evaluate the independent relationships between selected factors for characteristics of platelet functional state and local parameters of hemostasis in patients with ulcer bleeding. The significance threshold was set at $P<0.05$. Among the computer models that are used in risk estimation, logistic regression and artificial neural networks are the most widely used, mainly because they are relatively easy to build and often have excellent predictive ability. ${ }^{17}$ The receiveroperating characteristic (ROC) curve was used to select an 
optimal decision threshold. Sensitivity, specificity, and area under the ROC curve were used to evaluate this model. ${ }^{18}$

\section{Results}

Patient demographics and clinical characteristics for the two groups are shown in Table 1. In total, 178 patients $(71.2 \%)$ had a previous history of peptic ulcer disease and 69 patients $(29.8 \%)$ received nonsteroidal antiinflammatory drugs or aspirin. Acute peptic ulcer bleeding occurred in 185 men $(74.9 \% \pm 2.8 \%)$ of mean age $54.0 \pm 1.4$ years and in 62 women $(25.1 \% \pm 2.8 \%)$ of mean age $70.2 \pm 1.9$ years. In 130 cases, ulcer bleeding occurred

Table I Characteristics of patients with gastric and duodenal ulcer bleeding

\begin{tabular}{|c|c|c|}
\hline Parameters & $\begin{array}{l}\text { Sustained } \\
\text { hemostasis } \\
\text { group }\end{array}$ & $\begin{array}{l}\text { Unsustainable } \\
\text { hemostasis } \\
\text { group }\end{array}$ \\
\hline Patients (n) & 105 & 142 \\
\hline \multicolumn{3}{|l|}{ Gender } \\
\hline Female & $36(34.3 \% \pm 4.6 \%)$ & $26(18.3 \% \pm 3.2 \%)^{*}$ \\
\hline Male & $69(65.7 \% \pm 4.6 \%)$ & $116(81.7 \% \pm 3.2 \%)$ \\
\hline NSAID/aspirin use & $26(24.8 \pm 4.2)$ & $43(30.3 \pm 3.1 \%)$ \\
\hline \multicolumn{3}{|l|}{ Age (years) } \\
\hline Female patients & $68.5 \pm 3.5$ & $70 \pm 2.2$ \\
\hline Male patients & $54.0 \pm 2.3$ & $54.0 \pm 1.9$ \\
\hline Comorbidity & $58(55.2 \% \pm 4.8 \%)$ & $72(50.7 \% \pm 4.2 \%)$ \\
\hline Cardiovascular diseases & $42(40 \% \pm 4.8 \%)$ & $60(42.3 \% \pm 4.1 \%)$ \\
\hline $\begin{array}{l}\text { Digestive system } \\
\text { disorders }\end{array}$ & $16(15.2 \% \pm 3.5 \%)$ & $16(\mathrm{I} .3 \% \pm 2.7 \%)$ \\
\hline Portal hypertension & I (0.96\% $\pm 0.95 \%)$ & $8(5.6 \% \pm 1.9 \%)^{*}$ \\
\hline Tumors & I $(0.96 \% \pm 0.95 \%)$ & $5(3.5 \% \pm 1.5 \%)^{*}$ \\
\hline $\begin{array}{l}\text { Acute inflammatory } \\
\text { diseases }\end{array}$ & I (0.96\% 土 0.95\%) & $5(3.5 \% \pm 1.5 \%)^{*}$ \\
\hline Diabetes mellitus & $5(4.8 \% \pm 2.1 \%)$ & $2(1.4 \% \pm 0.9 \%)$ \\
\hline \multicolumn{3}{|l|}{ Ulcer location } \\
\hline Stomach body & $25(23.8 \% \pm 4.2 \%)$ & $30(21.1 \% \pm 3.4 \%)$ \\
\hline $\begin{array}{l}\text { Pyloric part of } \\
\text { stomach }\end{array}$ & $20(19 \% \pm 3.8 \%)$ & 31 (2I.8\% $\pm 3.5 \%)$ \\
\hline Duodenum & $54(51.4 \% \pm 4.9 \%)$ & $74(52.1 \% \pm 4.2 \%)$ \\
\hline Several ulcers & $6(5.7 \% \pm 2.3 \%)$ & 7 (4.9\% $\pm 1.8 \%)$ \\
\hline \multicolumn{3}{|l|}{ Ulcer size $(\mathrm{cm})$} \\
\hline Stomach body & $1.5 \pm 0.02$ & $1.2 \pm 0.2$ \\
\hline Pylorus & $\mathrm{I} .2 \pm 0.3$ & $1 \pm 0.2$ \\
\hline Duodenum & $0.8 \pm 0.05$ & $0.8 \pm 0.04$ \\
\hline Rebleeding & 14 (I3.3\% 土 3.3\%) & $54(38 \% \pm 4.1 \%)^{*}$ \\
\hline $\begin{array}{l}\text { Erythrocyte number } \\
\left(10^{12} \text { per L) }\right.\end{array}$ & $3 \pm 0.1$ & $2.9 \pm 0.1$ \\
\hline $\begin{array}{l}\text { Hemoglobin } \\
\text { concentration (g/L) }\end{array}$ & $98 \pm 3.1$ & $95 \pm 2.5$ \\
\hline Hematocrit & $28 \pm 1.3$ & $27 \pm 1.0$ \\
\hline Platelet number & $235 \pm 8.2$ & $223 \pm 9.5$ \\
\hline Leukocyte number & $7.9 \pm 0.2$ & $8 \pm 0.4$ \\
\hline
\end{tabular}

Notes: Data in table above is Median \pm standard error. *Statistically significant at $P<0.05$.

Abbreviation: NSAID, non-steroidal anti-inflammatory drug. in patients with comorbidities, including pathology of the cardiovascular system, digestive system diseases, and acute inflammatory processes. There was no gender difference in the frequency of cardiovascular pathology in patients with ulcer bleeding. Despite the similar frequency of comorbidity in the two groups, the spectrum of disease, which can be viewed as a background for ulcer complication and failure of hemostasis, was different in patients with sustained and unsustainable hemostasis. Disorders of thrombogenesis were found more often in patients with such comorbidities as cancer $(P<0.05)$, portal hypertension $(P<0.05)$, and acute inflammatory disease $(P<0.05)$.

According to endoscopic characteristics, the most common location of ulcers complicated by bleeding was the duodenum (128 patients; $51.8 \% \pm 2.6 \%$ ) rather than the gastric body and pylorus $(22.2 \% \pm 1.5 \%$ and $20.6 \% \pm 1.3 \%$ of patients, respectively). In 13 patients $(5.3 \% \pm 1.3 \%)$ several ulcers were found. However, location and size of ulcers were not related to the efficacy of hemostasis. Endoscopic study revealed active bleeding (Forrest class I) in 21 patients $(8.5 \% \pm 1.8 \%)$, with 121 cases $(48.9 \% \pm 3.2 \%)$ being in Forrest class IIA and IIB, $83(33.7 \% \pm 3.1 \%)$ being in Forrest class IIC, and $22(8.9 \% \pm 1.8 \%)$ being in Forrest class III.

There were no significant differences in coagulation system indices $(P>0.05)$ or platelet count between patients in the two groups; however, analysis of platelet aggregation showed a difference in platelet response to all agonists. Despite the absence of significant links between collagen-induced and thrombin-induced platelet aggregation and ulcer size or location, an association was found between platelet reactivity and endoscopic characteristics of hemostasis. The lowest platelet response to collagen and thrombin was detected in patients with Forrest class I $(P<0.001)$ or IIA-IIB $(P<$ 0.01). Decreased collagen-induced and thrombin-induced aggregation was associated with a reversible pattern of the curve, which can be explained by defective platelet degranulation or impairment of secondary agonist effects. To verify these points, we analyzed the platelet response to ADP and adenosine triphosphate, which are considered to be the main paracrine factors magnifying the effect of tissue (collagen) and coagulation system (thrombin) stimuli on platelets. Interestingly, characteristics of ADP-induced aggregation in patients with gastroduodenal ulcer bleeding were similar to thrombininduced and collagen-induced aggregation, ie, higher in patients with sustainable hemostasis and low or absent in cases with recent or active bleeding, respectively. There were significant differences in platelet aggregation induced by ADP $(P<0.01)$, collagen $(P<0.01)$, and thrombin $(P<0.001)$ 
in patients with different states of hemostasis according to endoscopic characteristics (Table 2 and Figure 1).

Analysis of purine signaling in platelets showed a decrease in ADP-induced platelet aggregation, the degree of which was associated with different endoscopic characteristics $(P<0.01)$ and correlated with the platelet response to thrombin $(r=0.714, P<0.001)$ and collagen $(r=0.584, P<0.01)$. Another association of platelet reactivity with clinical and instrumental data was shown during analysis of the effects of epinephrine and 5-HT. In vitro measurement of platelet aggregation induced by epinephrine showed a relationship with chronological characteristics. During the first 6 hours after manifestation of bleeding, high epinephrine-induced platelet aggregation was observed; however, decreased platelet adrenoreactivity was subsequently detected. This observation could reflect the phases of compensatory reaction by the sympathoadrenal system and time-dependent changes in platelet sensitivity to systemic regulators 12 hours after manifestation of ulcer bleeding. There was no significant relationship between size, Forrest class, severity of bleeding, and 5-HT-induced platelet aggregation.

Nevertheless, a relationship between the effect of 5-HT and location of the ulcer was shown, in that the least 5-HTinduced platelet aggregation was found in patients with gastric ulcers and highest values $(P<0.01)$ were found in cases of duodenal ulcer bleeding, which was associated with pathology of the gastrointestinal tract $(P<0.01)$.

Thus, analysis of the functional state of platelets in patients with gastroduodenal ulcer bleeding allowed us to establish the following: variability of platelet response to different agonists used in $\mathrm{EC}_{50}$; a relationship between platelet aggregation and spatial-temporal characteristics of ulcers complicated by bleeding; and an association between

Table 2 Platelet aggregation in patients with different characteristics of hemostasis

\begin{tabular}{|c|c|c|c|c|}
\hline \multirow[t]{2}{*}{$\begin{array}{l}\text { Substances } \\
\text { (agonists) }\end{array}$} & \multicolumn{2}{|c|}{$\begin{array}{l}\text { Sustainable } \\
\text { hemostasis group }\end{array}$} & \multicolumn{2}{|c|}{$\begin{array}{l}\text { Unsustainable } \\
\text { hemostasis group }\end{array}$} \\
\hline & $\begin{array}{l}\text { Median } \pm \\
\text { SE }\end{array}$ & $95 \% \mathrm{Cl}$ & $\begin{array}{l}\text { Median } \pm \\
\text { SE }\end{array}$ & $95 \% \mathrm{Cl}$ \\
\hline ADP & $69 \pm 5.9$ & $34-76$ & $12 \pm 4.8^{* *}$ & $5-20$ \\
\hline Epinephrine & $28 \pm 4.9$ & $21-35$ & $24 \pm 4.6$ & $16-32$ \\
\hline Collagen & $71 \pm 5.9$ & $64-85$ & $43 \pm 4.5^{*}$ & $33-50$ \\
\hline 5-hydroxytryptophan & $59 \pm 4.8$ & $45-73$ & $50 \pm 8.5$ & $33-64$ \\
\hline Thrombin & $75 \pm 4.5$ & $66-80$ & $27 \pm 5.0 * * *$ & $12-40$ \\
\hline
\end{tabular}

Notes: *Statistically significant at $P<0.05$; **statistically significant at $P<0.01$; ****statistically significant at $P<0.001$.

Abbreviations: ADP, adenosine diphosphate; $\mathrm{Cl}$, confidence interval; SE, standard error. platelet reactivity and different parameters of hemostasis and outcome.

Artificial neural network analysis was used to determine the variables that predict successful hemostasis. All clinical, endoscopic, laboratory, and platelet aggregation data were used as predictor variables for development of the artificial neural network model. Three variables were finally selected, ie, female/male (X1), ADP-induced (X2), and thrombininduced (X3) platelet aggregation. We developed the artificial neural network model based on these three predictors. The model ROC curve (Figure 2) was used to select an optimum decision threshold $\left(\mathrm{Y}_{\text {crit }}=0.74\right)$. This model can be represented by the equation:

$$
\mathrm{Y}=0.122 \times \mathrm{X} 1-0.00226 \times \mathrm{X} 2-0.00680 \times \mathrm{X} 3+1.157
$$

where $\mathrm{X} 1$ is 0 for female and $\mathrm{X} 1$ is 1 for male.

If the response value is $\mathrm{Y}<\mathrm{Y}_{\text {crit }}$, sustained hemostasis is predicted, and an alternative result corresponds to failure of hemostasis. On the training set, sensitivity was $68.8 \%$ (95\% confidence interval [CI] 54.7-81.2) and specificity was $73.2 \%$ (95\% CI 65.7-80.0). On the test set, sensitivity was $64.3 \%(95 \%$ CI $35.8-88.1)$ and specificity was $73.1 \%$ (95\% CI 53.8-88.7). There were no significant differences between the training and test sets $(P=0.82$ for sensitivity and $P=0.99$ for specificity). The area under the ROC curve was 0.77 (95\% CI $0.71-0.82$ ), the left margin of $95 \% \mathrm{CI}$ is more than 0.5 . This confirmed the validity of the model in terms of its ability to distinguish between sustained and unsustainable hemostasis.

To estimate the risk of unsustainable hemostasis for the three selected predictors, a logistic regression model was developed $\left(\chi^{2}=41.6\right.$ on three degrees of freedom, $\left.P<0.001\right)$. Table 3 summarizes the information for each variable in the model.

The results indicate that increased platelet aggregation induced by ADP significantly $(P=0.04)$ reduces the risk of unsustainable hemostasis, with an odds ratio of 0.86 (95\% CI 0.75-0.99) per each 10 points. Further, elevation of thrombin-induced aggregation also significantly $(P<0.001)$ decreased the risk of unsustainable hemostasis, with an odds ratio of $0.66(95 \%$ CI $0.54-0.79)$ per each 10 points.

\section{Discussion}

Although the etiology and pathogenesis of ulcer bleeding is thought to be multifactorial, nowadays it is evident that effective and adequate stratification of risk factors has the most consistent effect with regard to prevention 
ADP

A

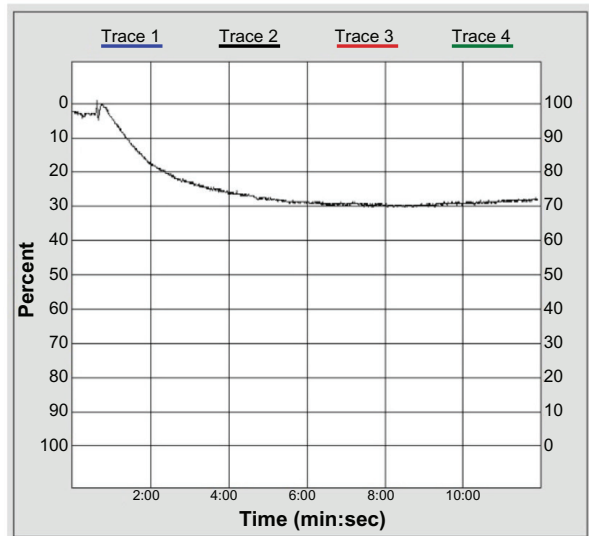

\section{Collagen}

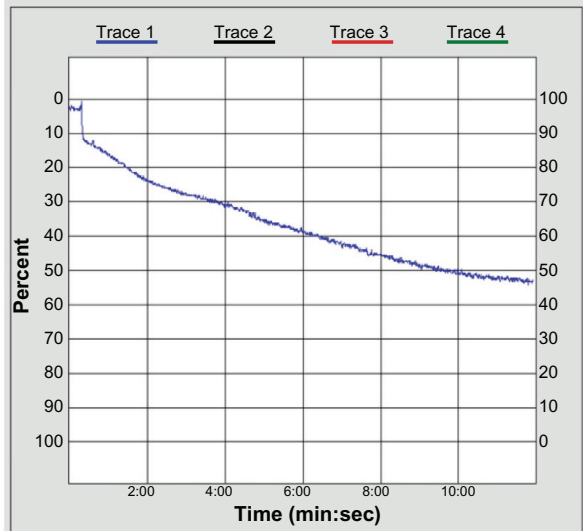

A Time (min:sec)

\section{Thrombin}

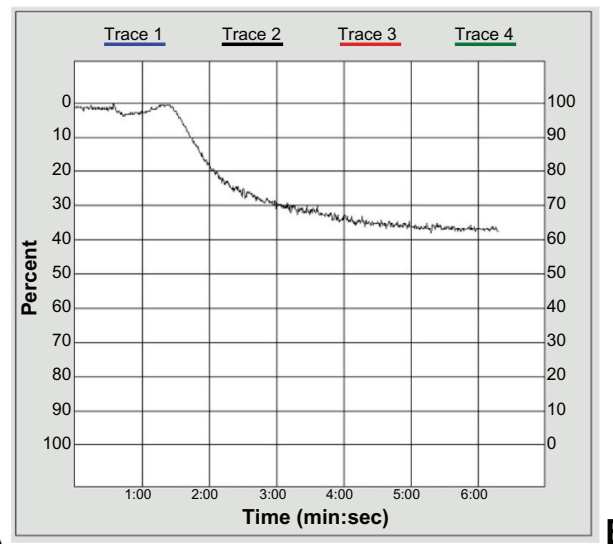

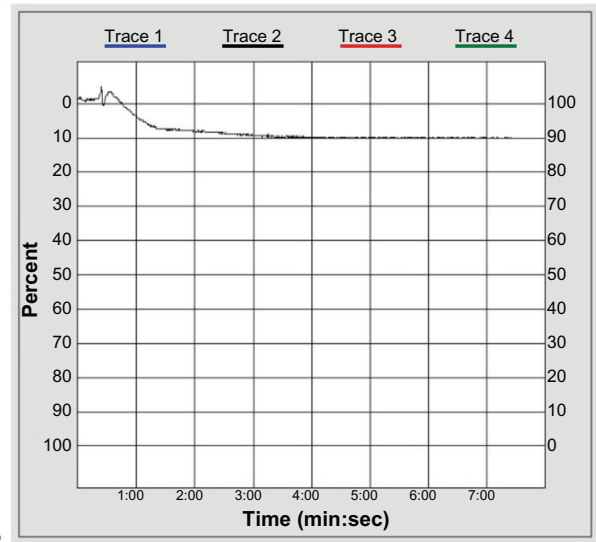

B

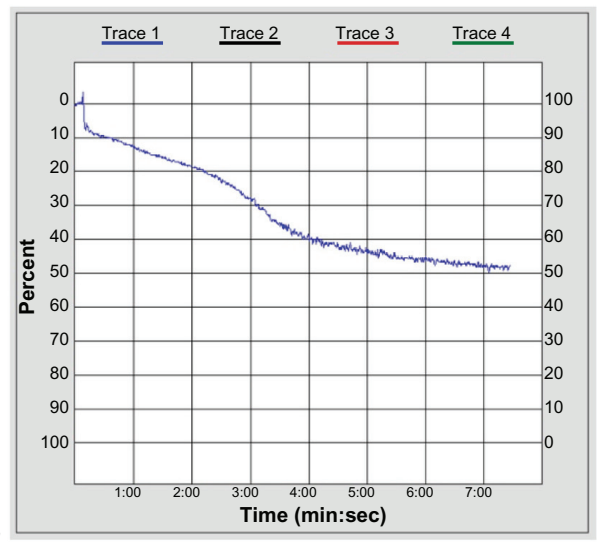

B Time (min:sec)

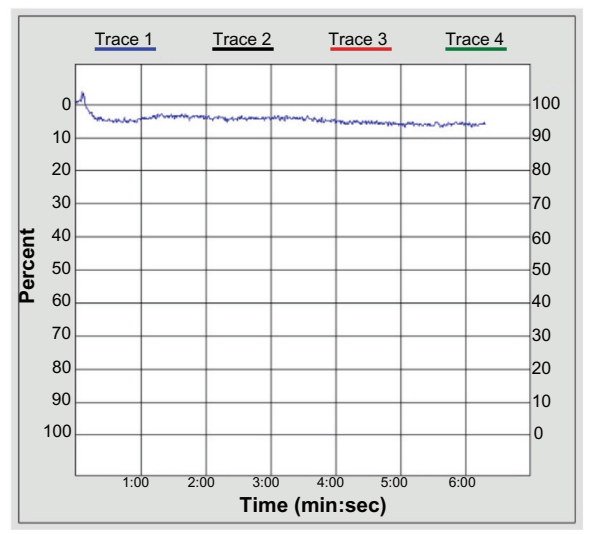

Figure I Platelet aggregation induced by adenosine diphosphate (ADP), collagen, and thrombin in patients with sustained (A) and unsustained hemostasis (B).

of rebleeding. ${ }^{4,6}$ It is the vital risk factor for mortality, and increases the risk five times compared with patients in whom bleeding has stopped spontaneously., ${ }^{5,12}$ The most widely known risk stratification tool for gastroduodenal bleeding is the Rockall scoring system, ${ }^{10,11}$ which is an accurate and validated predictor of rebleeding and mortality. ${ }^{15}$ This approach is perfect for short-term management of gastroduodenal bleeding, but not for development of a novel strategy for treatment and prevention of ulcer bleeding. Indeed, treatment of ulcer bleeding remains only partly successful, despite widespread use of endoscopic methods, eradication of Helicobacter pylori, and progress in antisecretory therapy. In our view, the solution may lie in the development of a new approach directed toward assessment of the mechanisms 


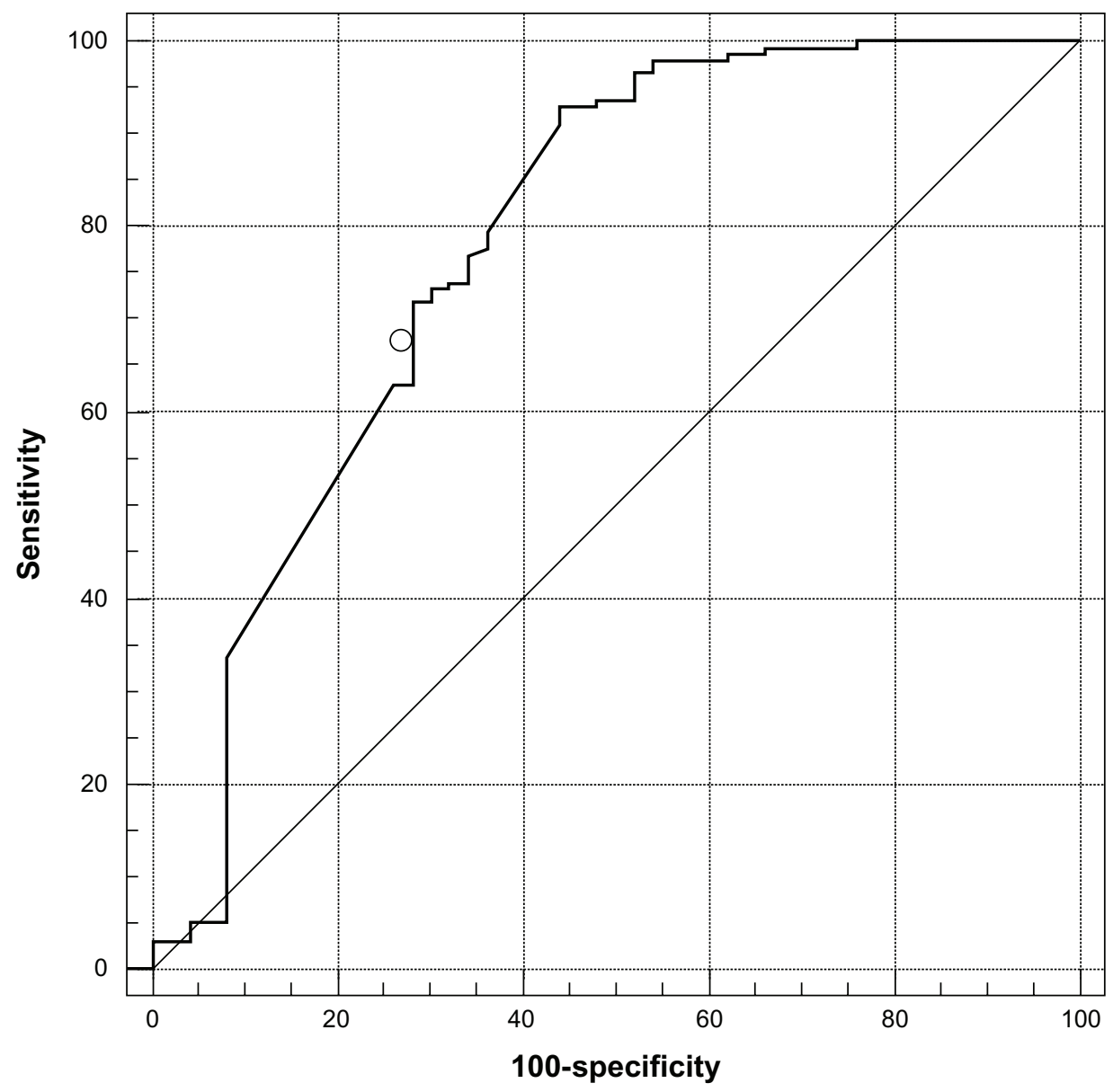

Figure 2 Receiver-operating characteristic curve for artificial neural network model predicting the failure of hemostasis. Note: o corresponds to the optimal value of sensitivity and specificity of the model.

involved in failure of hemostasis rather than on detection of stigmata of bleeding.

In this work, we analyzed the mechanisms of hemostasis failure in patients with gastroduodenal ulcer bleeding in vitro. Platelets were chosen as a model in order to study the mechanisms of unsustainable hemostasis. This choice is explained by the following facts: platelets are the first and obligatory participants in thrombogenesis; ${ }^{13}$ the platelet surfaces have numerous receptors, including protease activated

Table 3 Logistic regression model coefficients

\begin{tabular}{llll}
\hline Variable & $\begin{array}{l}\text { Parameter } \\
\text { estimate, } \\
\text { beta } \pm \text { SE }\end{array}$ & P-value & $\begin{array}{l}\text { Estimated } \\
\text { odds ratio } \\
\mathbf{( 9 5 \% ~ C l ) ~}\end{array}$ \\
\hline $\begin{array}{l}\text { Gender } \\
\text { ADP-induced }\end{array}$ & $-0.90 \pm 0.54$ & 0.10 & $0.41(0.14-1.20)$ \\
$\begin{array}{l}\text { platelet aggregation } \\
\text { Thrombin-induced } \\
\text { platelet aggregation }\end{array}$ & $-0.15 \pm 0.07$ & 0.04 & $0.86(0.75-0.99)$ \\
\hline
\end{tabular}

Abbreviations: $\mathrm{ADP}$, adenosine diphosphate; $\mathrm{Cl}$, confidence interval; $\mathrm{SE}$, standard error. receptors 1st and 4th types (PAR-1 and PAR-4) which react with thrombin and tissue factor; ${ }^{19}$ and platelets are the targets for different systemic factors involved in the reaction of the organism to bleeding, including epinephrine, norepinephrine, and 5 -HT. ${ }^{20}$

The molecular and functional characteristics of platelets can be informative in assessment of individual reactivity of the organism and the key mechanisms underlying defects in thrombogenesis. According to this concept, we assessed the efficacy of the platelet model for investigation of mechanisms of platelet dysfunction in patients with ulcer bleeding by in vitro analysis of platelet aggregation.

We found out that changes in agonist-induced platelet aggregation and hemostasis failure in patients with ulcer bleeding can reflect the role of systemic, tissue, paracrine, and coagulation factors in platelet dysfunction and failure of thrombogenesis. Specific relationships between the platelet response to different regulators and the spatial-temporal characteristics of ulcers and hemostasis characteristics were found. Platelet aggregation analysis showed significant 
differences in thrombin-induced aggregation between patients with bleeding that stopped spontaneously and those with active or recent bleeding. According to the results of modeling, successful hemostasis depends on gender and platelet aggregation induced by thrombin and ADP.

Thrombin is generally considered to be a potent inducer of platelet aggregation and usually induces high irreversible aggregation, ${ }^{21,22}$ so reduction of platelet reactivity in response to this agonist was a surprise. The thrombin effect on platelets is realized through PAR-1 and PAR-4, which are the most numerous types of receptors on platelets $(1,500-2,000$ per platelet), and also through glycoprotein (GP) Ib. ${ }^{13}$

Interestingly, a decreased platelet response to thrombin in some patients was associated with a normal reaction to weak agonists, such as ADP or epinephrine. This fact reflects agonist-specific changes in platelet reactivity that can be explained by changes in the expression and number of receptor molecules, their desensitization, impairment of PAR cleavage or shedding under inflammation, inhibition of thrombin linking to the GP Ib/IX/V complex, or changes in intracellular signaling of platelets, eg, due to activation of negative regulation of thrombogenesis. ${ }^{13,23}$

Moreover, thrombin is an integrative link between the plasma coagulation system, platelets, and the inflammatory reaction. ${ }^{24}$ On the one hand, it is involved in the regulation of hemostasis, and on the other is affected by numerous factors involved in the hemostatic and inflammatory systems. ${ }^{25,26}$ For example, heparin, the level of which is dramatically increased in the acute phase of ulcerogenesis and bleeding, can inhibit the effects of thrombin on platelet aggregation. ${ }^{13}$ It has been shown that heparin, by inhibiting the interaction between thrombin and GP Ib, might affect platelet activation by thrombin. ${ }^{27,28}$ The same antiplatelet effect has been described for the heavy chain of factor XIIa, as well as for high molecular weight kininogen, which inhibits thrombininduced platelet aggregation by binding to the platelet GP Ib/IX/V complex. ${ }^{29}$ There is also an alternative effect of activated protein $\mathrm{C}$ which links to PAR-1 and inhibits its cleavage by thrombin. ${ }^{13,30}$

Despite described mechanisms being discussed in numerous papers devoted to platelet biology and pathology, we should state that all these ways can reduce the initial stages of platelet aggregation. However, these data cannot explain the reversible nature of the aggregation curve in some patients. In fact, it could be related to alteration of mechanisms mediating granule secretion and/or stabilization of clot formation. Impairment of mechanisms mediating granule secretion might be an important issue in the decreased release of paracrine regulators and the defect in the propagation stage of thrombogenesis, which is especially important because, according to our modeling results, the risk of pathologic hemostasis increases significantly with combined failure of the platelet response to thrombin and ADP. It is well known that ADP is a weak agonist for platelet aggregation, and that this is explained by the low number of purine receptors on the platelet surface (about 150 per platelet). ${ }^{31}$ However, release of ADP from dense granules during primary induction and activation of two types of receptors ( $\mathrm{P} 2 \mathrm{Y}_{1}$ and $\left.\mathrm{P} 2 \mathrm{Y}_{12}\right)$ induces potent stimulation of $\mathrm{Gq}$ and $\mathrm{Gi}$ protein-associated signaling. ${ }^{32}$ The latter includes activation of phospholipase $\mathrm{C}$, inositol-3-phosphate, and protein kinase $\mathrm{C}$, release of calcium, and inhibition of adenylyl cyclase with additional stimulation of phosphatidylinositol-3-kinase $\gamma$, Akt, and Rap $1 \mathrm{~b}$, which provide potent amplification of the effect of primary agonists, including collagen and thrombin..$^{20,33}$ Finally the effect of ADP includes recruitment of new platelets into aggregation with progression of clot formation and activation of GP IIb-IIIa for the fibrinogen links necessary for clot stabilization. ${ }^{34}$ Alteration of the platelet response to purines can not only explain the failure of the propagation phase of thrombogenesis and reversible nature of the aggregation curve after potent agonist stimulation, but might also be a reason why the clot is not stabilized despite the high level of fibrinogen in plasma.

Another reason for the reversible aggregation could be abnormal thrombin-fibrinogen and platelet-fibrinogen interactions. This point is one of the most interesting and important because many patients with ulcer bleeding have increased levels of plasma fibrinogen. As is already known, thrombin substrate binding is mediated through fibrinogen recognition "exosite 1" in thrombin, resulting in fibrinopeptide cleavage to form fibrin, which is necessary for thrombus stabilization. Plasma fibrinogen molecules containing gamma' chains ("fibrinogen 2") are virtually all heterodimers containing one gamma(A) chain (platelet-binding) and one gamma' chain. The remaining fibrinogen (approximately 85\%) is homodimeric, lacks high affinity thrombin-binding potential, and is termed "fibrinogen 1" $[\operatorname{gamma}(\mathrm{A}) / \operatorname{gamma}(\mathrm{A})]$. The last one can inhibit PAR-1 cleavage and thus prevent the effect of thrombin on platelets. ${ }^{35}$

Interpreting this finding, it is necessary to underline that PAR-1 is expressed not only on the platelet surface but also on vascular endothelium, fibroblasts, gut myofibroblasts, and leukocytes, which are all involved in inflammation and tissue repair. ${ }^{36}$ The results of our study show significant differences in platelet state between patients with high risk and low risk 
of rebleeding, that is directly related to ulcer healing efficacy. It is well known that the hemostasis system is tightly linked to such fundamental processes as inflammation and regeneration. ${ }^{37}$ Consequently, platelets and their reactivity could be considered as a perfect target for investigation of healing mechanisms. Platelets are increasingly being viewed as important contributors to healing. ${ }^{38}$ This is attributable to the many proangiogenic and antiangiogenic factors stored within platelet granules, which can be released at the site of a lesion. ${ }^{13}$ These properties raise the interesting question of whether platelets can be used in the treatment of peptic ulcers complicated by bleeding.

Experimental models and clinical observations indicate that platelets play a pivotal role in healing of the skin and mucosa by releasing a number of growth factors that can promote angiogenesis, which is an essential process for ulcer healing and requires concerted interaction between a number of cellular systems. ${ }^{39,40}$ The essential regulator of angiogenesis is vascular endothelial growth factor (VEGF). VEGF is a highly specific mitogen for vascular endothelial cells, promotes endothelial proliferation and migration, and has been shown to accelerate ulcer healing significantly. ${ }^{41}$ VEGF is stored in $\alpha$-granules within the platelet and released during platelet activation. ${ }^{42}$ In addition to VEGF, platelet granules contain platelet-derived growth factor and transforming growth factor- $\beta$, which stimulate myofibroblast proliferation and secretory activity as well as formation of granulation tissue. ${ }^{13}$ That is why platelets are thought to be a good tool for improving healing. Topical application of autologous derived platelet-rich plasma gel may become the new way of treating ulcers because of therapeutic delivery of numerous growth factors involved in the healing process. ${ }^{37-39}$

Previous studies have shown that circulating platelets contribute significantly to gastric ulcer healing, acting as a delivery system for these growth factors at the site of injury. An animal study showed that platelets accelerated gastric ulcer healing by increasing VEGF levels at the site of injury. ${ }^{40}$ However, these results were obtained in patients and animals without bleeding. Nonetheless, use of autologous derived platelet-rich plasma gel in the treatment of ulcers is limited and its application in patients with ulcer bleeding is debatable. As shown in our research, ulcer bleeding was associated with platelet dysfunction and a decrease in platelet aggregation induced by different regulatory factors that can be associated with abnormalities of granule secretion. ${ }^{23}$ Because aggregation of platelets is tightly related to granule secretion and release of growth factors, platelet dysfunction in patients with ulcer bleeding can lead to a lack of the expected morphogenic effect.
Another important factor is that platelet granules contain not only growth factors stimulating regeneration but also antiangiogenic substances like endostatin. The concentration of proangiogenic and antiangiogenic factors in platelets is dynamic, and depends on the quality of the platelet development program (megakaryocytopoiesis), which is controlled by numerous factors, including cytokines and hormones. Moreover, the content and release of regulators of angiogenesis can be affected by antiplatelet drugs. For instance, it had been shown that administration of ticlopidine not only inhibits ADP-induced platelet aggregation and resulting $\alpha$-granule and VEGF release, but also increases platelet endostatin content by approximately $50 \%{ }^{39}$

The next interesting fact is that balancing of the VEGF and endostatin content in platelets can be changed during neoplastic process. Convincing evidence was obtained in research that has shown an increase in endostatin levels in the platelets of rats with silent tumors and an increase in VEGF during tumor progression. ${ }^{43}$ Despite the fact that tumor progression and ulcer bleeding are unrelated conditions, these results should be taken into account because of the chronic inflammatory process in patients with gastroduodenal ulcers. It is known that the development of gastric ulcers as a rule is associated with atrophic gastritis, which is suggested to be a precancer state. Indeed, atrophic gastritis is associated with atrophy of gastric glands, hypergastrinemia, and hyperhistaminemia, increased proliferation, defective epithelial cell differentiation and life span regulation, which lead to impairment of the gastrointestinal barrier and maintaining of cell alterations, and is thought to be a high risk factor for tumor transformation. ${ }^{41}$ Therefore, application of platelet-rich gel can have unpredictable results in such conditions.

Another intriguing fact is the different mechanisms of VEGF and endostatin release. If VEGF release depends on granule secretion stimulated by thrombin through PAR-1, the release of endostatin is activated through PAR-4. ${ }^{44}$ Therefore, selective activation or desensitization of some receptors can modulate the effect of platelets on angiogenesis and healing. Selective stimulation of PAR-1 is associated with release of VEGF. ${ }^{45}$ However, a decrease in thrombin-induced aggregation due to desensitization of PARs can be associated with a decrease in secretory activity and growth factors release.

Assessment of the effects of thrombin on platelets is even more interesting given that PARs are widely expressed in the gastrointestinal tract and involved in tissue growth and regeneration. ${ }^{46}$ It is well known that PAR-1 is expressed on endothelium and perivascular fibroblasts and that it is 
involved in angiogenesis and regeneration of connective tissue. ${ }^{47}$ That is why we hypothesized that local application of selective agonists of PAR-1 might be beneficial for correction of hemostasis and improvement of gastroduodenal healing in patients with peptic ulcers.

Thus, estimation of platelet reactivity in vitro provides an indication of the key mechanisms of hemostasis failure in patients with ulcer bleeding. In addition to the gender factor, the important determinant of unsustainable hemostasis was a decreased platelet response to thrombin and ADP.

\section{Acknowledgments}

The authors thank Viktoria Delii and Kate Gatina for technical assistance, and the staff from the laboratory (Tatiana Tverdokhleb and Anastasia Balykina) of the M Gorky Donetsk National Medical University for their efforts.

\section{Disclosure}

The authors report no conflicts of interest in this work.

\section{References}

1. Laursen SB, Jorgensen HS, Schaffalitzky de Muckadell OB; Danish Society of Gastroenterology and Hepatology. Management of bleeding gastroduodenal ulcers. Dan Med J. 2012;59(7):C4473.

2. Knoefel WT, Rehders A. Chirurgische Therapiekonzepte bei oberer gastrointestinaler Blutung. [Gastrointestinal bleeding - concepts of surgical therapy in the upper gastrointestinal tract.] Chirurg. 2006;77(2):126-132. German.

3. Bratanic A, Puljiz Z, Ljubicic N, et al. Predictive factors of rebleeding and mortality following endoscopic hemostasis in bleeding peptic ulcers. Hepatogastroenterology. 2012;60(121):112-117.

4. Laine L, Jensen DM. Management of patients with ulcer bleeding. Am J Gastroenterol. 2012;107(3):345-360.

5. Jensen DM. Ulcer: prediction and prevention of peptic ulcer rebleeding. Nat Rev Gastroenterol Hepatol. 2012;9(1):7-8.

6. Holster IL, Kuipers EJ. Update on the endoscopic management of peptic ulcer bleeding. Curr Gastroenterol Rep. 2011;13(6):525-531.

7. Zhang JY, Wang Y, Zhang J, et al. [Risk factors associated with failure from endoscopic therapy in acute non-variceal upper gastrointestinal bleeding.] Beijing Da Xue Xue Bao. 2010;42(6):703-707. Chinese.

8. Hu ML, Wu KL, Chiu KW, et al. Predictors of rebleeding after initial hemostasis with epinephrine injection in high-risk ulcers. World $J$ Gastroenterol. 2010;16(43):5490-5495.

9. Rotondano G, Cipolletta L, Grossi E, et al. Artificial neural networks accurately predict mortality in patients with nonvariceal upper GI bleeding. Gastrointest Endosc. 2011;73(2):218-226.

10. Lebedev NV, Klimov AE. [Treatment protocol of gastrointestinal bleedings.] Khirurgiia (Mosk). 2009;11:10-13. Russian.

11. Martins NB, Wassef W. Upper gastrointestinal bleeding. Curr Opin Gastroenterol. 2006;22(6):612-619.

12. Marmo R, Koch M, Cipolletta L, et al; Italian registry on upper gastrointestinal bleeding (Progetto Nazionale Emorragie Digestive- PNED 2). Predicting mortality in non-variceal upper gastrointestinal bleeders: validation of the Italian PNED score and prospective comparison with the Rockall score. Am J Gastroenterol. 2010;105(6):1284-1291.

13. Michelson AD. Platelets. 2nd ed. Boston, MA: Elsevier Inc; 2007.

14. Alexandru N, Popov D, Georgescu A. Platelet dysfunction in vascular pathologies and how can it be treated. Thromb Res. 2012;129(2): $116-126$.
15. Rotondano G, Cipolletta L, Grossi E, et al. Artificial neural networks accurately predict mortality in patients with nonvariceal upper GI bleeding. Gastrointest Endosc. 2011;73(2):218-226.

16. Michelson AD. Methods for the measurement of platelet function. Am J Cardiol. 2009;103:20A-26A.

17. Ayer T, Chhatwal J, Alagoz O, Kahn CE Jr, Woods RW, Burnside ES. Comparison of logistic regression and artificial neural network models in breast cancer risk estimation. Radiographics. 2010;30(1):13-22.

18. Petrie A, Sabin C. Medical Statistics at a Glance. 2nd ed. Malden, MA: Blackwell Publishing; 2005.

19. Rao LV, Pendurthi UR. Regulation of tissue factor coagulant activity on cell surfaces. J Thromb Haemost. September 24, 2012. [Epub ahead of print.]

20. Stalker TJ, Newman DK, Ma P, et al. Platelet signaling. Handb Exp Pharmacol. 2012;210:59-85.

21. Schlagenhauf A, Kozma N, Leschnik B, et al. Thrombin receptor levels in platelet concentrates during storage and their impact on platelet functionality. Transfusion. 2012;52(6):1253-1259.

22. Licari LG, Kovacic JP. Thrombin physiology and pathophysiology. $J$ Vet Emerg Crit Care (San Antonio). 2009;19(1):11-22.

23. Goggs R, Poole AW. Platelet signaling - a primer. J Vet Emerg Crit Care (San Antonio). 2012;22(1):5-29.

24. O'Brien M. The reciprocal relationship between inflammation and coagulation. Top Companion Anim Med. 2012;27(2):46-52.

25. Ma L, Dorling A. The roles of thrombin and protease-activated receptors in inflammation. Semin Immunopathol. 2012;34(1):63-72.

26. Jennewein C, Paulus P, Zacharowski K. Linking inflammation and coagulation: novel drug targets to treat organ ischemia. Curr Opin Anaesthesiol. 2011;24(4):375-380.

27. Petaja J. Inflammation and coagulation. An overview. Thromb Res. 2011;127 Supp1 2:S34-S37.

28. Levi M, van der Poll T. Inflammation and coagulation. Crit Care Med. 2010;38(Suppl 2):S26-S34.

29. Bradford HN, Pixley RA, Colman RW. Human factor XII binding to the glycoprotein Ib-IX-V complex inhibits thrombin-induced platelet aggregation. J Biol Chem. 2000;275(30):22756-22763.

30. De Candia E. Mechanisms of platelet activation by thrombin: a short history. Thromb Res. 2012;129(3):250-256.

31. Gachet C. P2Y(12) receptors in platelets and other hematopoietic and non-hematopoietic cells. Purinergic Signal. 2012;8(3):609-619.

32. Moheimani F, Jackson DE. P2Y(12) receptor: platelet thrombus formation and medical interventions. Int J Hematol. 2012;96(5):572-587.

33. Bynagari-Settipalli YS, Lakhani P, Jin J, et al. Protein kinase C isoform epsilon negatively regulates ADP-induced calcium mobilization and thromboxane generation in platelets. Arterioscler Thromb Vasc Biol. 2012;32(5):1211-1219.

34. Lombardi F, De Chaumont C, Shields DC, Moran N. Platelet signaling networks: pathway perturbation demonstrates differential sensitivity of ADP secretion and fibrinogen binding. Platelets. 2012;23(1):17-25.

35. Lovely RS, Rein CM, White TC, et al. GammaA/gamma' fibrinogen inhibits thrombin-induced platelet aggregation. Thromb Haemost. 2008;100(5):837-846.

36. Trejo J. Protease-activated receptors: new concepts in regulation of G protein-coupled receptor signaling and trafficking. $J$ Pharmacol Exp Ther. 2003;307(2):437-442.

37. Perini R, Wallace JL, Ma L. Roles of platelets and proteinase-activated receptors in gastric ulcer healing. Dig Dis Sci. 2005;50 Suppl 1:S12-S15.

38. Akingboye AA, Giddins S, Gamston P, Tucker A, Navsaria H, Kyriakides C. Application of autologous derived-platelet rich plasma gel in the treatment of chronic wound ulcer: diabetic foot ulcer. $J$ Extra Corpor Technol. 2010;42(1):20-29.

39. Ma L, Elliott SN, Cirino G, Buret A, Ignarro LJ, Wallace JL. Platelets modulate gastric ulcer healing: role of endostatin and vascular endothelial growth factor release. Proc Natl Acad Sci U S A. 2001;98(11): 6470-6475.

40. Wallace JL, Dicay M, McKnight W, Dudar GK. Platelets accelerate gastric ulcer healing through presentation of vascular endothelial growth factor. Br J Pharmacol. 2006;148(3):274-278. 
41. Tarnawski AS. Cellular and molecular mechanisms of gastrointestinal ulcer healing. Dig Dis Sci. 2005;50 Suppl 1:S24-S33.

42. Battinelli EM, Markens BA, Italiano JE. Release of angiogenesis regulatory proteins from platelet alpha granules: modulation of physiologic and pathologic angiogenesis. Blood. 2011;118(5):1359-1369.

43. Nava A, Giannoula LK. Platelet proteome and tumor dormancy: can platelets content serve as predictive biomarkers for exit of tumors from dormancy? Cancers. 2010;2(2):842-858.

44. Ma L, Perini R, McKnight W, et al. Proteinase-activated receptors 1 and 4 counter-regulate endostatin and VEGF release from human platelets. Proc Natl Acad Sci U S A. 2005;102(1):216-220.
45. Lang NN, Guðmundsdóttir IJ, Newby DE. Vascular PAR-1: activity and antagonism. Cardiovasc Ther. 2011;29(6):349-361.

46. Kawabata A, Nishikawa H, Saitoh H, et al. A protective role of protease-activated receptor 1 in rat gastric mucosa. Gastroenterology. 2004;126(1):208-219.

47. Perini R, Wallace JL. Proteinase-activated receptors (PARs), platelets and angiogenesis. Drug Dev Res. 2003;59(4):395-399.

\section{Publish your work in this journal}

Clinical and Experimental Gastroenterology is an international, peerreviewed, open access journal, publishing all aspects of gastroenterology in the clinic and laboratory, including: Pathology, pathophysiology of gastrointestinal disease; Investigation and treatment of gastointestinal disease; Pharmacology of drugs used in the alimentary tract;
Immunology/genetics/genomics related to gastrointestinal disease. This journal is indexed on CAS. The manuscript management system is completely online and includes a very quick and fair peer-review system. Visit http://www.dovepress.com/testimonials.php to read real quotes from published authors.

Submit your manuscript here: http://www.dovepress.com/clinical-and-experimental-gastroenterology-journal 